\title{
Cross Platform Aplikasi Manajemen Data Karyawan pada PT Maxindo Mitra Solusi
}

\author{
Angga Eko Pratama ${ }^{1, *}$, Agus Junaidi ${ }^{2}$, Rudianto ${ }^{3}$, Yunita ${ }^{4}$ \\ 1,2,3 STMIK Nusa Mandiri, Jakarta - 11730, Indonesia \\ ${ }^{4}$ Universitas Bina Sarana Informatika, Jakarta - 10450, Indonesia \\ ${ }^{1}$ angganix@ gmail.com*; ${ }^{2}$ agus.asj@ bsi.ac.id; ${ }^{3}$ rudianto.rdt@ bsi.ac.id, ${ }^{4}$ yunita.yut@ nusamandiri.ac.id \\ corresponding Author*
}

\section{NF O A R T I K E L}

Article History:

Received January 1, 2020

Revised January 21, 2020

Accepted February 12, 2020

Available Online February 14, 2020

\section{Keywords:}

Cross-Platform

Employee data

Human Resources Application,

Mobile Hybrid Application,

RAD

\section{Keywords:}

Cross-Platform,

Data Karyawan,

Aplikasi Sumber Daya Manusia,

Mobile Hybrid Application,

RAD

\section{Korespondensi:}

Telephon: +62 85951218906

E-mail: angganix@gmail.com

\section{ABSTRACT}

Data management of a company's employees still uses the Microsoft Excel application to store data, which makes searching, managing, and archiving data difficult. HR staff regularly input data to Microsoft Excel files when changes occur. When HR collects work shift schedule data, it must wait for supervisors to provide schedules and give them to the HR staff. Making an application to manage human resources requires a fast method. Intensive communication with stakeholder to find out the problems and expectations of the application to be built in the target of the RAD method. This method was chosen because the process of making the application will be completed quickly according to the request. The application is made to apply the Cross-Platform concept by utilising mobile hybrid application technology, so that the target application will be opened on various device platforms, such as desktop, web, and smartphone. Application tested by the black-box testing method that focused to user form input for check any form input is valid or not. By making applications using the RAD method, applications that are made can be implemented directly to staff, divisions, and the HRD. Employee data management applications can be operated after passthrough black box testing on a variety of platforms such as desktops, the web, and smartphones. So HR staff can manage employee data with valid and easily without having to rely on one application platform.

\begin{tabular}{l} 
ABSTRAK \\
\hline Manajemen data karyawan sebuah perusahaan masih menggunakan aplikasi microsoft \\
excel untuk menyimpan data, yang menyebabkan pencarian, pengelolaan, dan arsip data \\
sulit dilakukan. Para staff HRD melakukan input data secara berkala dan melakukan \\
pengecekan terhadap file microsoft excel ketika terjadi perubahan. belum lagi HRD \\
mengumpulkan data jadwal shift kerja, hal itu harus menunggu para supervisor \\
memberikan cetak jadwal dan memberikannya ke HRD untuk dapat di masukan ke dalam \\
rekap absensi bulanan. Membuatkan sebuah aplikasi untuk mengelola sumber daya \\
manusia dibutuhkan metode yang cepat. Melakukan komunikasi secara intens terhadap \\
pihak HRD untuk mengetahui masalah dan harapan aplikasi yang akan dibangun \\
merupakan target dari metode RAD. Metode ini dipilih karena proses pembuatan aplikasi \\
akan cepat selesai disesuaikan oleh permintaan staff HRD. Aplikasi yang dibuat \\
menerapkan konsep Cross-Platform dengan memanfaatkan teknologi mobile hybrid \\
application, sehingga target aplikasi akan dapat dibuka diberbagai platform device, seperti \\
desktop, web, dan smartphone. Pengujian aplikasi dilakukan menggunakan black box \\
testing yang berfokus pada inputan pengguna dengan tujuan melakukan cek terhadap form \\
input apakah sudah sesuai atau belum. Dengan melakukan pembuatan aplikasi \\
menggunakan metode RAD, aplikasi yang dibuat dapat di implementasikan secara \\
langsung kepada staff, divisi, dan pihak HRD. Aplikasi manajemen data karyawan dapat \\
dioperasikan setelah melalui pengujian black-box testing dan dapat berjalan di berbagai \\
platform seperti desktop, web, dan smartphone. Sehingga staff HRD dapat melakukan \\
pengelolaan data karyawan dengan benar dan mudah tanpa harus bergantung pada satu \\
platform aplikasi.
\end{tabular}

\section{Pendahuluan}

PT Maxindo Mitra Solusi merupakan perusahaan yang bergerak di bidang Internet Service Provider. Memberikan pelayanan kepada customer baik untuk pelanggan baru maupun yang telah menjalani kontrak. 
Di perusahaan ini, sistem pendataan karyawan masih menggunakan aplikasi spreadsheet, dengan melakukan input data ke dalam software aplikasi microsoft excel. Membuat pencarian data karyawan, pengelolaan jadwal shift, dan penilaian karyawan kurang efektif, dikarenakan file yang digunakan tidak terorganisir secara sistematis, hanya sebagai penyimpanan data statik, dimana perubahan data harus dilakukan secara manual.

Penilaian kinerja karyawan dalam sebuah perusahaan merupakan tolak ukur berhasil atau tidaknya tujuan dari perusahaan tersebut. Karena dengan melakukan penilaian kinerja karyawan akan menghasilkan fungsi-fungsi atau indikator pekerjaan yang dapat dihasilkan dari pekerjaan yang dilakukan dalam waktu tertentu [1].

HRD memerlukan aplikasi yang mendukung proses pendataan SDM agar pendataan karyawan lebih efektif dan maksimal. Informasi mengenai sumber daya manusia pada sebuah perusahaan sangatlah dibutuhkan untuk menunjang kinerja, baik dari karyawan maupun untuk perusahaan [2]. Dengan permasalahan tersebut, dibutuhkan sebuah aplikasi yang dapat menggantikan peran microsoft excel dalam menyimpan data karyawan serta komponennya, agar lebih terorganisir dan teratur, serta memudahkan para staff HRD dalam melakukan pencarian, manajemen data, dan arsip data.

Oleh karena itu, penelitian ini dirancang untuk membuat sebuah aplikasi manajemen data karyawan, yang dapat memberikan solusi terhadap permasalahan yang terjadi. Aplikasi yang dibuat diharapkan dapat memberikan akses mudah bagi para staff HRD maupun karyawan dalam melihat informasi dan mengelola data sumber daya manusia yang ada.

\section{Metode Penelitian}

Penelitian dilakukan dengan menggunakan jenis eksperimen dengan tahapan sebagai berikut:

\subsection{Observasi}

Dalam mengumpulkan data dan permasalahan, penulis melakukan pengamatan secara langsung pada bagian HRD di PT Maxindo Mitra Solusi. Pengamatan tersebut dilakukan selama satu bulan, dengan mengamati data yang digunakan untuk pengelolaan data karyawan.

\subsection{Wawancara}

Untuk memastikan pengamatan yang dilakukan, penulis melakukan wawancara dengan manajer HRD di PT Maxindo Mitra Solusi guna menggali informasi dan mendapatkan penjelasan tentang pengelolaan data yang berjalan.

\subsection{Studi Pustaka}

Penulis melakukan pengumpulan informasi dengan mengambil dua sumber data yang mendukung perancangan aplikasi manajemen data karyawan. Data yang dimaksud adalah data primer, yaitu data sistem berjalan yang digunakan oleh perusahaan PT Maxindo Mitra Solusi berupa file excel dan dokumen penilaian karyawan. Selain itu penulis juga mengambil informasi data sekunder dengan mencari referensi dari beberapa jurnal terdahulu dan buku-buku terkait dengan sistem informasi dan teknologi.

\section{Penelitian Terdahulu}

Selain melakukan penelitian terhadap sumber data utama dan studi pustaka penulis melakukan perbandingan terhadap penelitian terdahulu yang membahas pembuatan aplikasi sumber daya manusia, salah satu referensi yang di ambil penulis adalah dari [3] yang membahas tentang pembuatan aplikasi untuk melakukan pendataan karyawan dalam bentuk sistem yang mudah didistribusikan dan digunakan oleh pihak HRD perusahaan, dengan aplikasi yang dibuat bertujuan untuk membantu manajer dalam pengambilan keputusan dalam hal prestasi maupun jenjang karir.

Penulis melakukan pengembangan ide dengan membuatkan sistem aplikasi sumber daya manusia yang dapat melakukan pendataan, penjadwalaan kerja, serta penilaian kerja karyawan yang dijadikan dalam satu 
aplikasi berbasis cross platform. Jika pada penelitian sebelumnya peneliti membuatkan aplikasi berbasis web, pada penelitian ini penulis berfokus pada pembuatan aplikasi yang dapat digunakan pada jenis sistem operasi yang berbeda baik sistem operasi desktop maupun mobile yang biasa disebut cross platform atau multiplatform [4]. Selain itu penulis juga menggunakan teknologi AJAX dalam melakukan proses request terhadap script php pada sisi server, dimana AJAX ini akan membantu proses request data dari sisi client (browser) ke server dengan asynchronous (tidak langsung) sehingga halaman yang melakukan request tidak perlu melakukan load halaman secara penuh [5].

\section{Model Pengembangan Sistem dengan Rapid Application Development (RAD)}

Dalam membuat sistem aplikasi ini, penulis menggunakan model RAD (Rapid Application Development), dikarenakan kecepatan dan interaksi terhadap pengguna aplikasi yang terus-menerus dilakukan guna menghasilkan aplikasi yang diharapkan. Rapid Aplication Development (RAD) adalah sebuah model perkembangan software yang menekankan siklus pembuatan aplikasi yang sangat pendek (sekitar 2 sampai 3 bulan). Model RAD ini merupakan sebuah adaptasi "kecepatan tinggi" dari model sekuensial linier dimana perkembangan cepat dicapai dengan menggunakan pendekatan konstruksi berbasis komponen [6]. Menurut Pressman [7] jika setiap kebutuhan dari masing-masing ruang lingkup proyek telah diketahui maka proses RAD akan membuat para tim pembuat software dapat mengerjakannya lebih cepat.

\subsection{Tahapan Model RAD}

Dalam model RAD terdapat lima tahapan yang perlu dilakukan dalam pembuatan software, tahapan tersebut [8] adalah sebagai berikut:

- Bisnis Model

Dalam tahapan ini, penulis dan staff HRD berdiskusi dalam menentukan kebutuhan aplikasi dan spesifikasinya. Menentukan peran atau hal apa saja yang dapat dilakukan untuk masing-masing objek. serta memberikan pembatasan hak akses antara administrator, supervisor, dan karyawan.

\section{- Permodelan Data}

Dalam tahapan ini, penulis merancang kebutuhan basis data menggunakan Data Modelling sesuai kasus yang sedang berjalan. Membuatkan listing tabel-tabel yang dibutuhkan serta relasi antar tabel.

- Permodelan Proses

Semua kegiatan yang berjalan dalam proses bisnis pengelolaan data karyawan saat ini, di transformasikan menjadi objek yang bekerja sesuai fungsinya. Model proses bisnis yang dibuat menggunakan activity diagram.

- Pembuatan Aplikasi

Tahapan ini merupakan pembuatan aplikasi sesuai model yang sudah dibuat, menyesuaikan tabel dari database dan di buatkan coding program agar dapat melakukan operasi CRUD (Create Read Update Delete). Proses ini dilakukan secara iteratif (berulang) dan meminta staff HRD memberikan masukan atau tambahan sesuai kebutuhan yang di inginkan.

- Pengujian

Dalam tahapan ini, penulis melakukan pengujian dan penjelasan dalam menggunakan program aplikasi yang telah dibuat (final). Serta memberikan pelatihan terhadap objek-objek yang terkait dengan sistem aplikasi yang telah dibuat. 


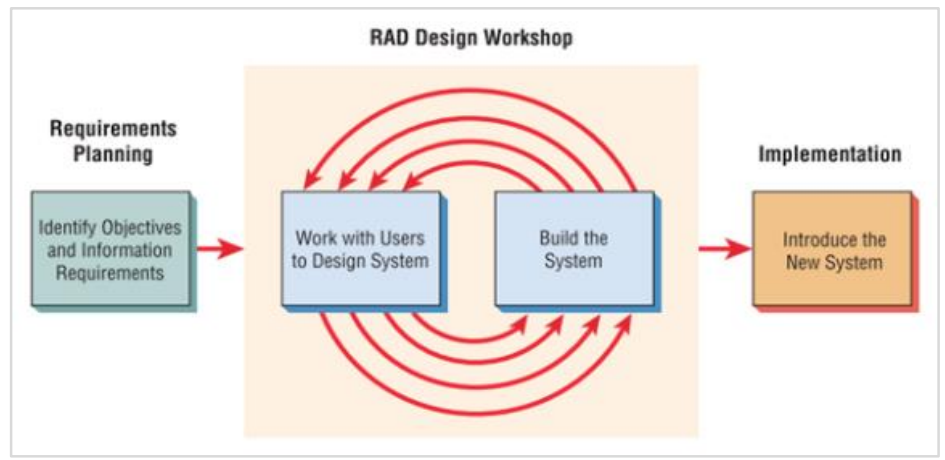

Sumber: [9]

Gambar 1. Skema Model RAD

Pada gambar skema model RAD di atas secara garis besar, proses pembuatan aplikasi dilakukan secara tim dengan melibatkan pengguna yang melakukan permintaan pembuatan modul aplikasi, hal ini dilakukan agar modul yang dibuat sesuai dengan permintaan pengguna.

\section{Hasil dan Pembahasan}

Pembuatan aplikasi manajemen data karyawan dengan menerapkan model Rapid Application Development dapat dilakukan dengan mengikuti langkah-langkap permodelan yang telah dijelaskan, berikut pembahasannya:

\subsection{Permodelan Bisnis}

Dalam tahapan ini penulis melakukan observasi dan wawancara terhadap pihak HRD untuk mendapatkan informasi terkait data yang dibutuhkan serta scope sistem yang akan dibuat dengan membuatkan use case diagram dengan fish level untuk menggambarkan apa saja yang dapat dilakukan dari masing-masing scope.

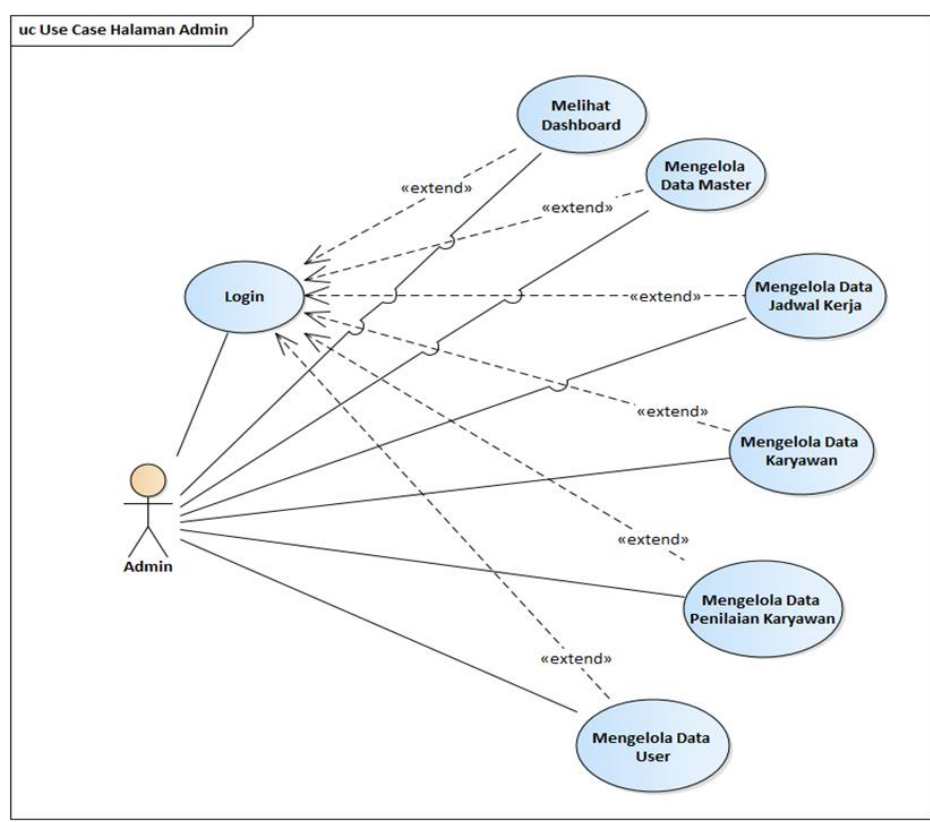

Sumber: Hasil Penelitian (2019)

Gambar 2. Use Case Diagram Halaman Admin

Use Case halaman admin menunjukkan peran dari administrator dalam mengelola modul dashboard, data master, jadwal kerja, data karyawan, penilaian karyawan, dan melakukan manajemen data pengguna aplikasi. 


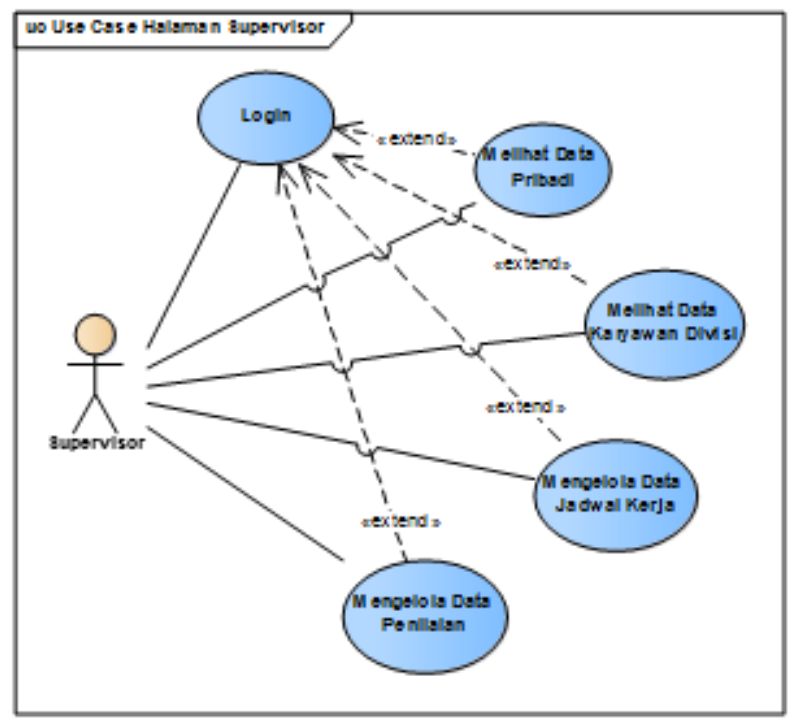

Sumber: Hasil Penelitian (2019)

Gambar 3. Use Case Diagram Halaman Supervisor

Use Case Halaman supervisor menunjukkan peran dari supervisor divisi dalam mengelola modul data pribadi, data karyawan divisi, jadwal kerja, dan data penilaian dengan melakukan login aplikasi terlebih dahulu.

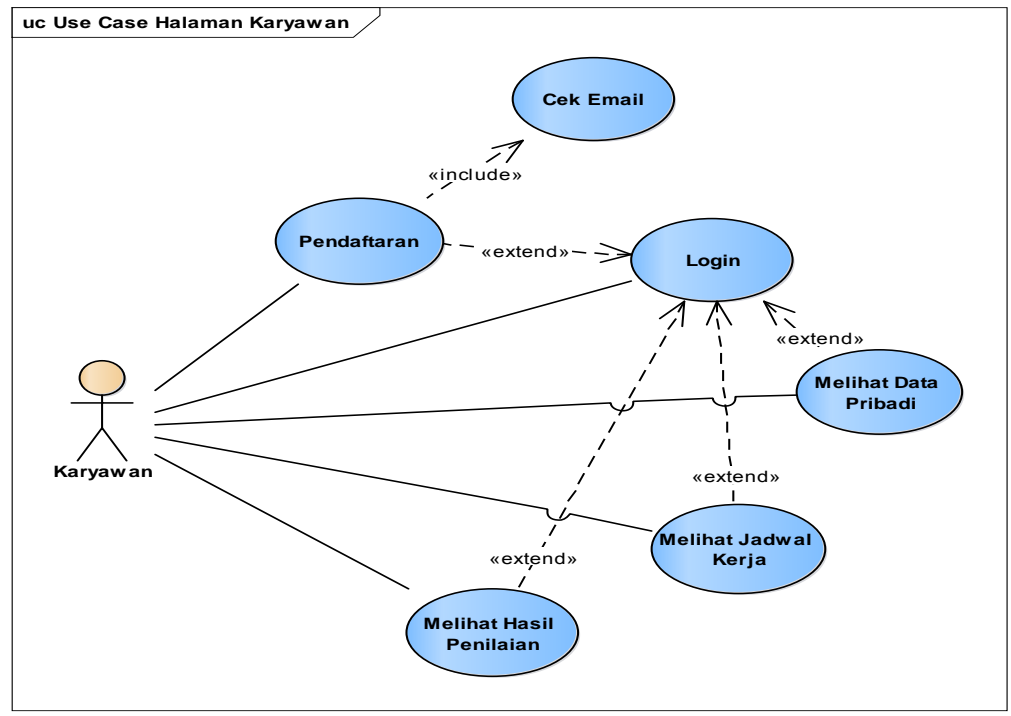

Sumber: Hasil Penelitian (2019)

Gambar 4. Use Case Diagram Halaman Karyawan

Use Case halaman karyawan menunjukkan peran dari karyawan dalam mengelola modul data pribadi, melihat jadwal kerja, dan melihat hasil penilaian dengan melakukan pendaftaran akun terlebih dahulu pada aplikasi dan melakukan login ke sistem.

\subsection{Permodelan Data}

Dalam Tahapan Ini penulis merancang susunan kerangka basis data dan tabel-tabel yang dibutuhkan untuk menyimpan data-data aplikasi manajemen data karyawan sesuai hasil diskusi dengan staff HRD.

Dalam hal ini penulis menggunakan logical data model agar penggambaran keterkaitan antar tabel lebih mudah di visualisasi. Table-tabel utama yang dibuat dalam pembuatan aplikasi manajemen data karyawan adalah sebagai berikut: 
- Employees $\quad$ : Tabel untuk menyimpan data karyawan

- Schedule : Tabel untuk menyimpan data jadwal karyawan

- Employee Assessment : Tabel untuk menyimpan data penilaian karyawan

- Work Status $\quad$ : Tabel untuk menyimpan data status kerja karyawan

Adapun table-tabel pendukung lainnya sebagai detail data utama adalah sebagai berikut:

- $\quad$ Card Types

- Cards

- Work History

- Work Location

- Division

- Position

- Shift Role

- Schedule Detail

- Assessment Form data penilaian seperti table Item Penilaian, Definisi Penilaian, dan Indikator Penilaian
: Tabel untuk menyimpan data master kartu

: Tabel untuk menyimpan data kartu karyawan

: Tabel untuk menyimpan riwayat jabatan karyawan

: Tabel untuk menyimpan data master lokasi kerja

: Tabel untuk menyimpan data master divisi

: Tabel untuk menyimpan data master jabatan

: Tabel untuk menyimpan data shift kerja

: Tabel untuk menyimpan detail data jadwal kerja

: Tabel untuk menyimpan hubungan Antara hasil penilaian dan master 


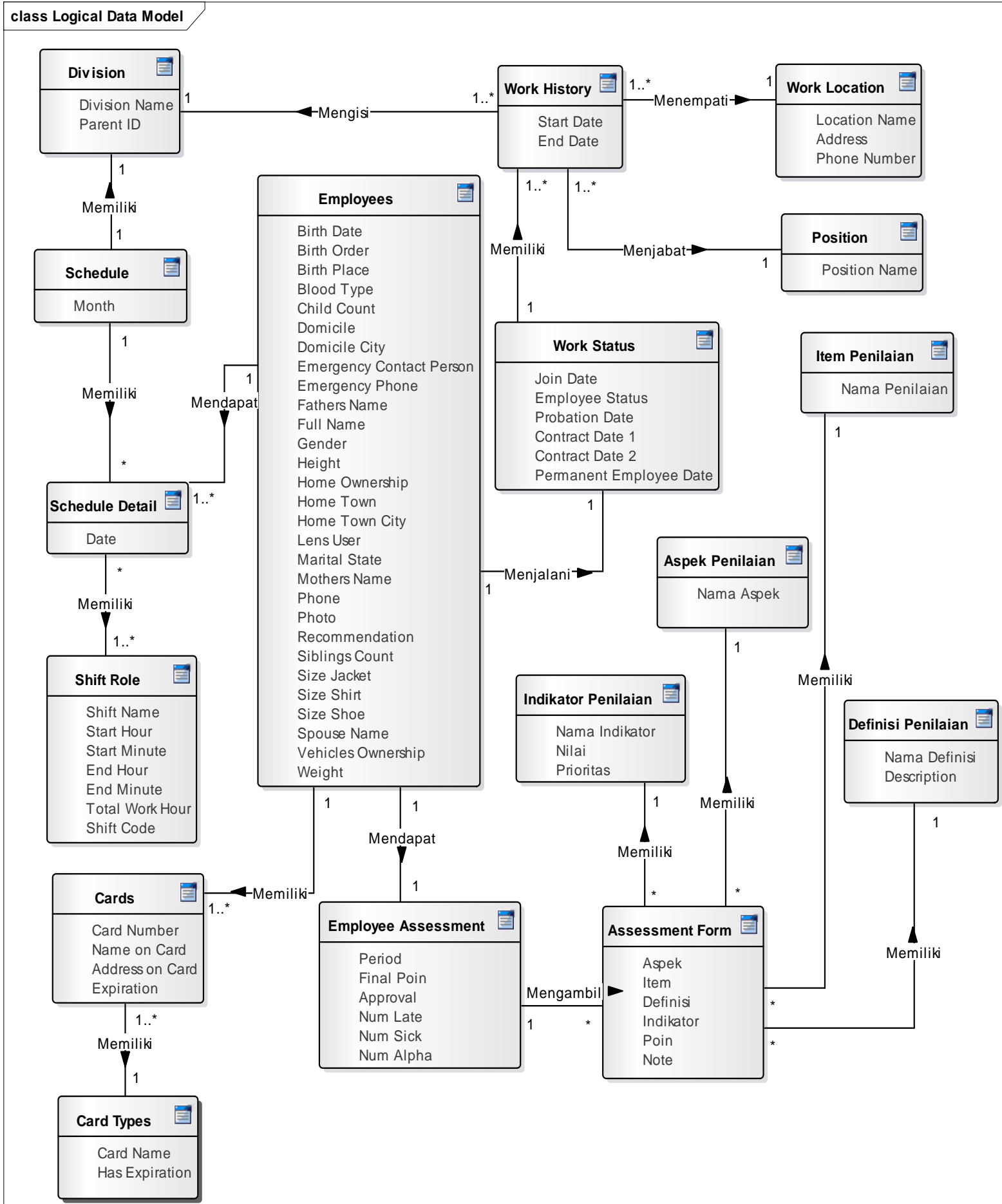

Sumber: Hasil Penelitian (2019)

Gambar 5. Logical Data Model

\subsection{Permodelan Proses}

Dalam permodelan proses penulis membuatkan flow control aplikasi dimana alur dari masing-masing peran divisualisasikan dengan activity diagram 


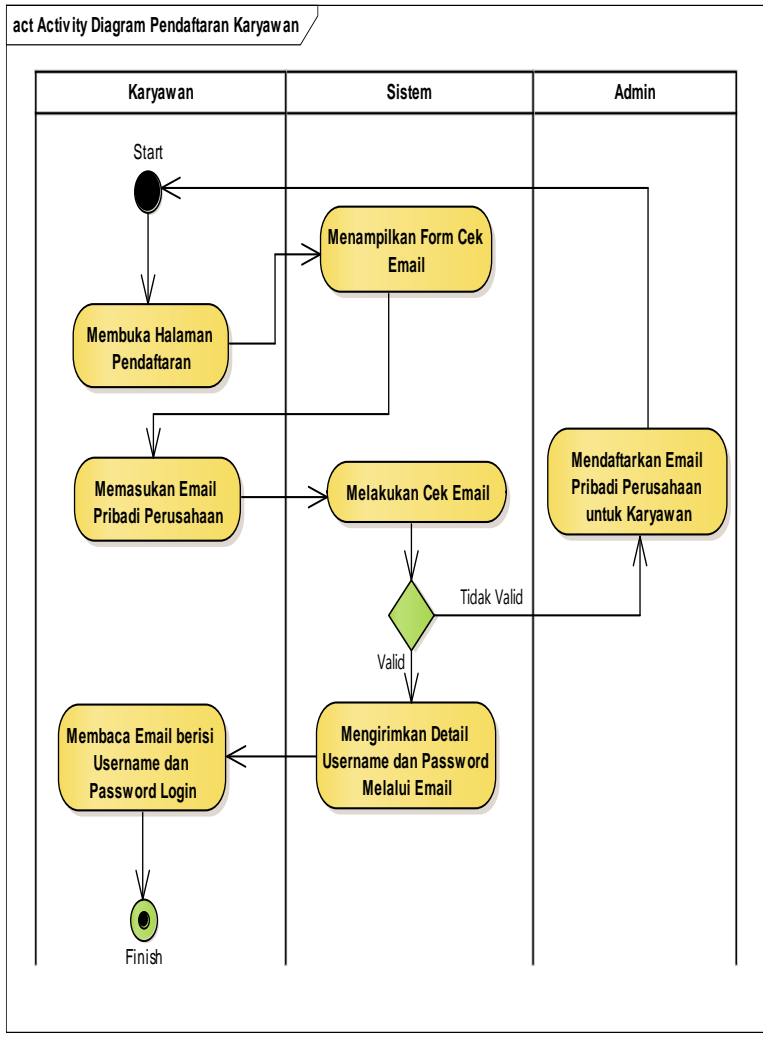

Sumber: Hasil Penelitian (2019)

Gambar 6. Activity Diagram Pendaftaran Karyawan

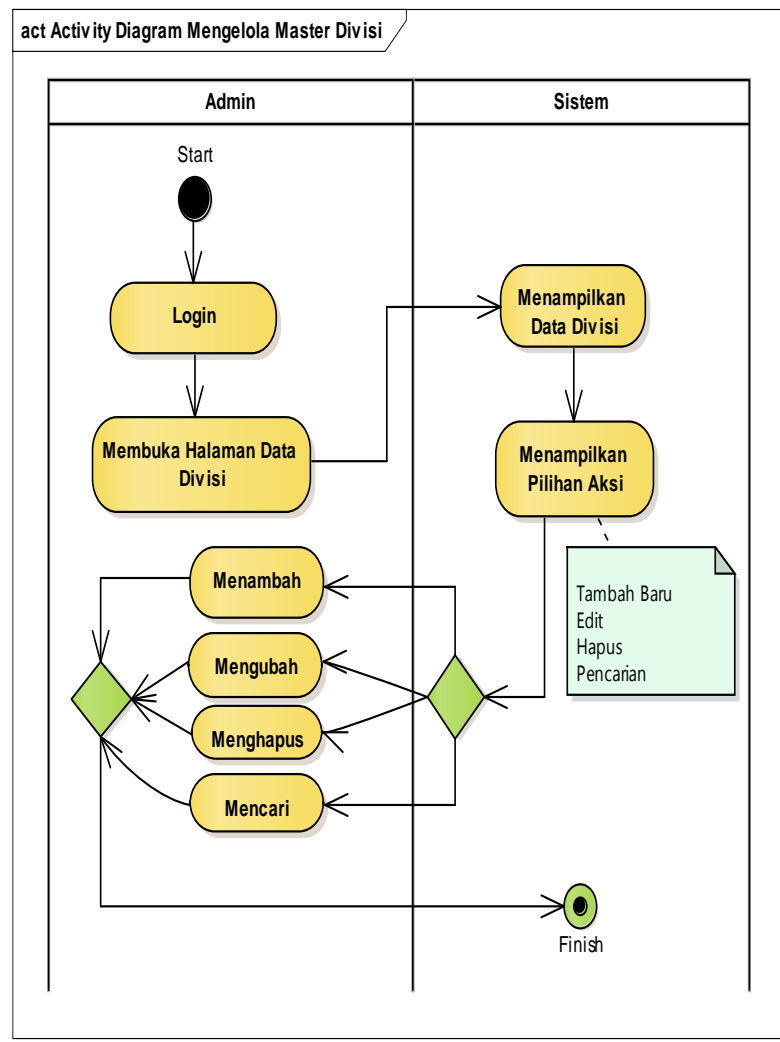

Sumber: Hasil Penelitian (2019)

Gambar 7. Activity Diagram Mengelola Data Master

Gambar 6. merupakanActivity Diagram melakukan pendaftaran karyawan baru. Gambar 7. Activity Diagram mengelola data master, activity diagram ini sama dengan proses CRUD (Create Read Update Delete) pada modul lainnya.

\subsection{Pembuatan Aplikasi}

Tahapan ini merupakan implementasi dari hasil rancangan desain permodelan sebelumnya sehingga membentuk form-form data yang siap digunakan untuk testing, sebelum digunakan secara live. Berikut ini merupakan contoh hasil dari pembuatan aplikasi yang siap untuk dilakukan testing.

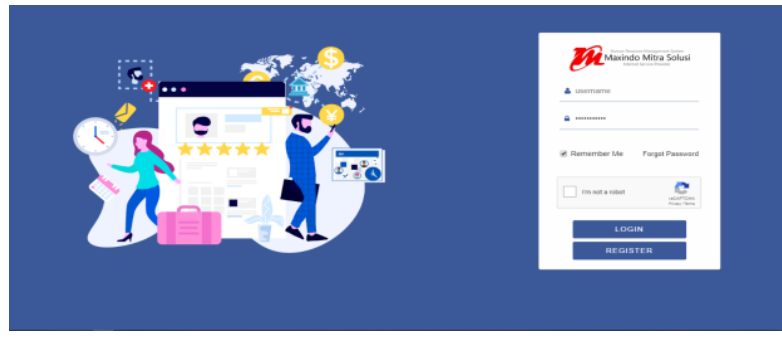

Sumber: Hasil Penelitian (2019)

Gambar 8. Halaman Login

Halaman login aplikasi untuk melakukan otentikasi terhadap pengguna yang akan masuk ke system.

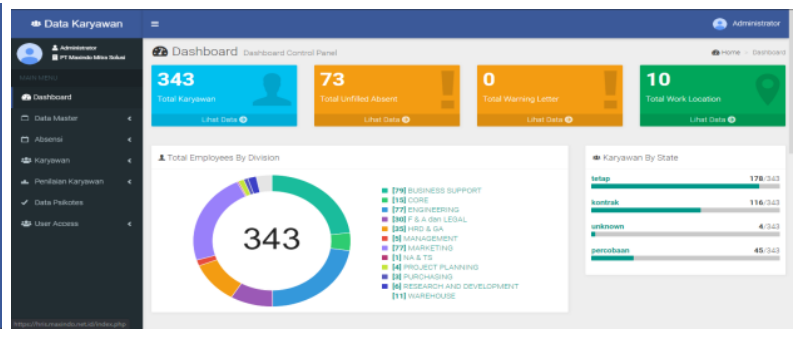

Sumber: Hasil Penelitian (2019)

Gambar 9. Halaman Dashboard Admin

Halaman dashboard untuk menampilkan summary data dari aplikasi manajemen data karyawan 


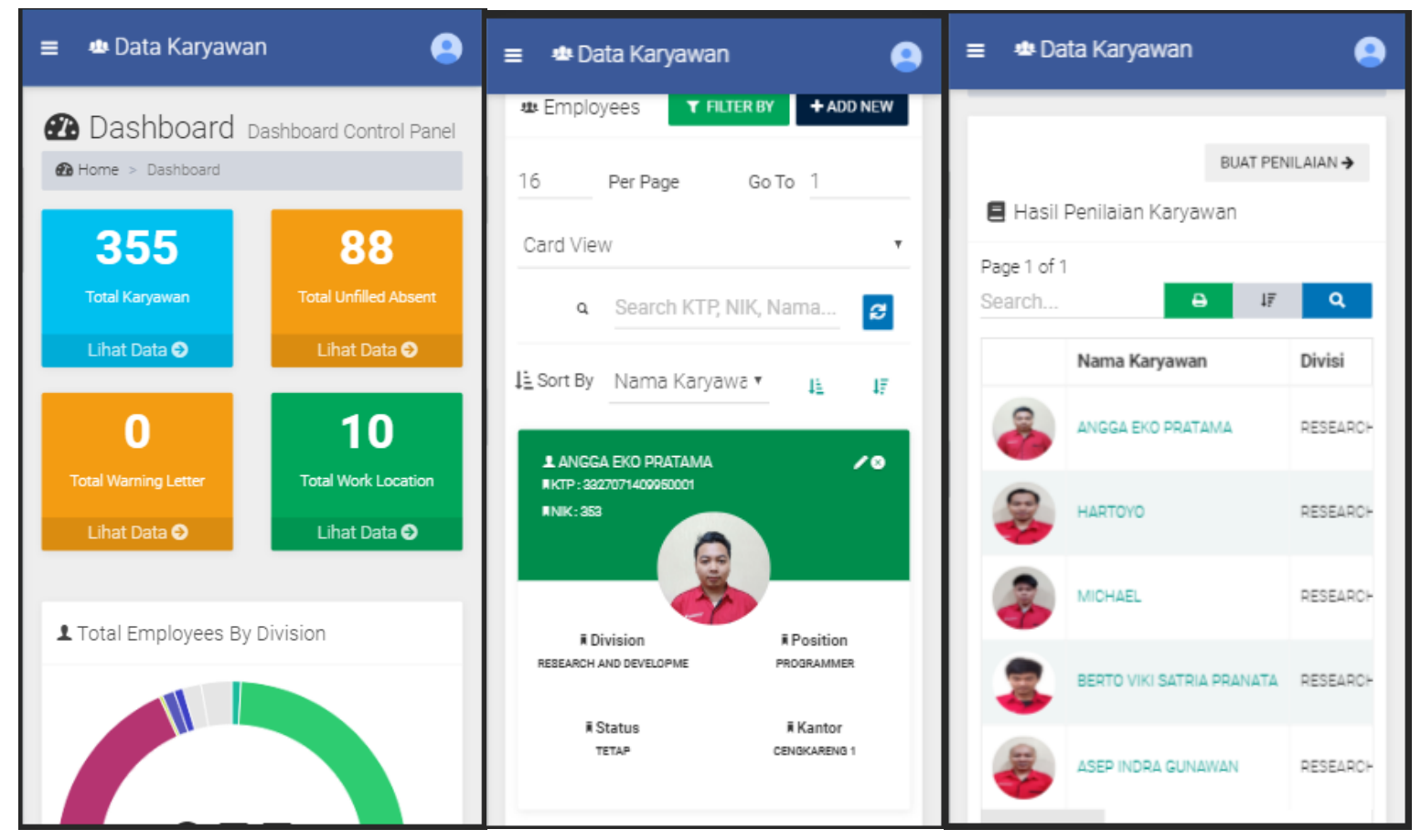

Sumber: Hasil Penelitian (2019)

Gambar 10. Hybrid Mobile Application (Tampilan aplikasi pada device mobile smartphone)

\subsection{Pengujian Aplikasi}

Sebelum aplikasi dapat didistribusikan, penulis melakukan pengujian menggunakan black box testing untuk melakukan validasi apakah input dari form pengguna sudah sesuai yang diharapkan atau belum. Pengujian black box menitikberatkan pada form input dan fungsi-fungsi kontrol pengguna dari berbagai kondisi untuk mencari tahu valid atau tidaknya hasil pengujian [10].

Table 1. Black box testing pada form pendaftaran karyawan baru

\begin{tabular}{|c|c|c|c|c|c|}
\hline No. & Skenario Pengujian & Test Case & Hasil yang diharapkan & Hasil Pengujian & Kesimpulan \\
\hline 1. & $\begin{array}{l}\text { Email maxindo tidak } \\
\text { diisi lalu klik cek email }\end{array}$ & Email (kosong) & $\begin{array}{l}\text { Muncul pesan "Email, tidak } \\
\text { ditemukan. Mohon hubungi } \\
\text { pihak HRD untuk } \\
\text { mengajukan penambahan } \\
\text { Email Karyawan" proses } \\
\text { pendaftaran di tolak }\end{array}$ & Sesuai harapan & valid \\
\hline 2. & $\begin{array}{l}\text { Email maxindo diisi } \\
\text { lalu klik cek email }\end{array}$ & $\begin{array}{l}\text { Email: } \\
\text { angga.eko.pratama } \\
\text { @ maxindo.net.id } \\
\text { (benar \& sudah } \\
\text { terdaftar) }\end{array}$ & $\begin{array}{l}\text { Muncul pesan “User with } \\
\text { email: } \\
\text { angga.eko.pratama@ maxin } \\
\underline{\text { do.net.id, already exists!" }} \\
\text { proses pendaftaran ditolak }\end{array}$ & Sesuai harapan & valid \\
\hline 3. & $\begin{array}{l}\text { Email maxindo diisi } \\
\text { lalu klik cek email }\end{array}$ & $\begin{array}{l}\text { Email: } \\
\text { hartoyo.asp@maxin } \\
\frac{\text { do.net.id (benar \& }}{\text { belum terdaftar) }}\end{array}$ & $\begin{array}{l}\text { Muncul pesan "kode } \\
\text { verifikasi anda akan } \\
\text { dikirimkan melalui email, } \\
\text { klik OK untuk } \\
\text { melanjutkan" sistem akan } \\
\text { mengirimkan email detil } \\
\text { OTP pendaftaran ke email } \\
\text { yang telah didaftarkan }\end{array}$ & Sesuai harapan & valid \\
\hline
\end{tabular}




\section{Kesimpulan}

Dari pembahasan sebelumnya dapat ditarik kesimpulan, bahwa dalam proses pendataan karyawan lebih efektif menggunakan aplikasi atau software yang telah dibuat, karena aplikasi ini dapat di akses melalui tiga platform yaitu web, desktop, dan mobile smartphone. Dan dengan menggunakan metode RAD dalam proses pembuatannya, modul-modul yang dibutuhkan oleh HRD akan cepat dibuatkan oleh tim software development karena model RAD berfokus pada konstruksi berbasis komponen, sehingga memanfaatkan class-class yang sudah dibuat untuk selanjutnya dapat digunakan kembali. Dengan melakukan pengujian black box maka kesalahan pengguna (human error) dapat dihindari untuk mencegah terjadinya blank error atau error tanpa adanya informasi atau pesan yang diberikan oleh sistem.

\section{Referensi}

[1] G. Taufiq, "Implementasi Logika Fuzzy Tahani Untuk Model Sistem Pendukung Keputusan Evaluasi Kinerja Karyawan,” J. Pilar Nusa Mandiri, vol. 12, no. 1, pp. 12-20, 2016.

[2] N. K. Wardhani and M. T. Abdul Azis, "Sistem Informasi Manajemen Sumber Daya Manusia Berbasis Web (Studi Kasus: PT. Klik Teknologi Indonesia)," J. TECHNO Nusa Mandiri, vol. 15, pp. 145-151, 2018.

[3] A. Setiawan, I. Handriani, and Saepurrahman, "Sistem Pencatatan Dan Pendataan Manajemen Sumber Daya Manusia Dengan Model Scrum ( Studi Kasus : Pt Bintang Trans Khatulistiwa )," JSAI, vol. 2, pp. 105-115, 2019.

[4] M. Nuraminudin, E. Utami, and H. Al Fatta, "Perancangan E-Customer Relationship Management Berbasis Cross Platform Memanfaatkan Web Service Pada Perusahaan Software House," J. Inform. DAN Teknol. Inf., vol. 3, no. 2, pp. 129-138, 2018.

[5] R. Abdulloh, Membuat Toko Online dengan Teknik OOP, MVC, dan AJAX. Jakarta: PT Elex Media Komputindo, 2017.

[6] W. W. Widiyanto, "Analisa Metodologi Pengembangan Sistem Dengan Perbandingan Model Perangkat Lunak Sistem Informasi Kepegawaian Menggunakan Waterfall Development Model, Model Prototype, Dan Model Rapid Application Development (Rad)," J. Inf., vol. 4, no. 1, pp. 34-40, 2018.

[7] V. Riyanto, "Implementasi Metode Rapid Application Development Dalam Membangun ECommerce Di Bidang UKM," J. Pilar Nusa Mandiri, vol. 13, no. 1, pp. 122-127, 2017, doi: 10.1016/S0001-2092(06)62131-5.

[8] Frieyadie, "Model Rapid Application Development Untuk Rancang Bangung Sistem Informasi Tempat Pemakaman Umum," J. Ilmu Pengetah. dan Teknol. Komput., vol. 2, no. 2, pp. 7-14, 2017.

[9] A. Safira and R. Gama Harta Nugraha Nur, "Implementasi Sistem Enterprise Resource Planning Berbasis Odoo Modul Sales Dengan Metode RAD Pada PT XYZ," J. Ind. Serv., vol. 5, no. 1, pp. 49-58, 2019.

[10] T. Hidayat and M. Muttaqin, "Pengujian Sistem Informasi Pendaftaran dan Pembayaran Wisuda Online menggunakan Black Box Testing dengan Metode Equivalence Partitioning dan Boundary Value Analysis," J. Tek. Inform. UNIS JUTIS, vol. 6, no. 1, pp. 25-29, 2018. 